\title{
National Ignition Facility SubSystem Design Requirements Target Positioning Subsystem SSDR 1.8.2
}

\author{
L. Pittenger
}

October 24, 1996

This is an informal report intended primarily for internal or limited external distribution. The opinions and concluoions atated are those of the author and may or may not be those of the Laboratory.

Work performed under the auspices of the U.S. Department of Energy by the Lawrence Livermore National Laboratory under Contract W-7405-Eng-48. 


\section{DISCLAIMER}

This document was prepared as an account of work sponsored by an agency of the United States Government. Neither the United States Government nor the University of California nor any of their employees, makes any warranty, express or implied, or assumes any legal liability or responsibility for the accuracy, completeness, or usefulness of any information, apparatus, product, or process disclosed, or represents that its use would not infringe privately owned rights. Reference herein to any specific commercial product, process, or service by trade name, trademark, manufacturer, or otherwise, does not necessarily constitute or imply its endorsement, recommendation, or favoring by the United States Government or the University of California. The views and opinions of authors expressed herein do not necessarily state or reflect those of the United States Covernment or the University of California, and shall not be used for advertising or product endorsement purposes.

This report has been reproduced directly from the best available copy.

Available to DOE and DOE contractors from the Office of Scientific and Technical Information

P.O. Box 62, Oak Ridge, TN 37831

Prices available from (615) 576-8401, FTS 626-8401

Available to the public from the National Technical Information Service

U.S. Department of Commerce 5285 Port Royal Rd. Springfield, VA 22161 


\section{National Ignition Facility}

\section{Subsystem Design Requirements}

\section{Target Positioning Subsystem \\ SSDR 1.8 .2}

Revision 2

24 October, 1996

Prepared by:

L. Pittenger, Target Positioning Lead Engineer

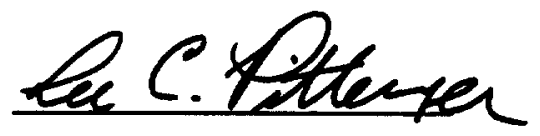

Date

$10 / 1 / 96$

Reviewed:

V. Karpenko, Target Experimental System Engineer

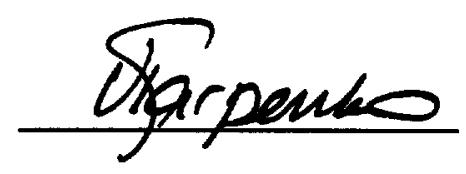

Date

9/23/96

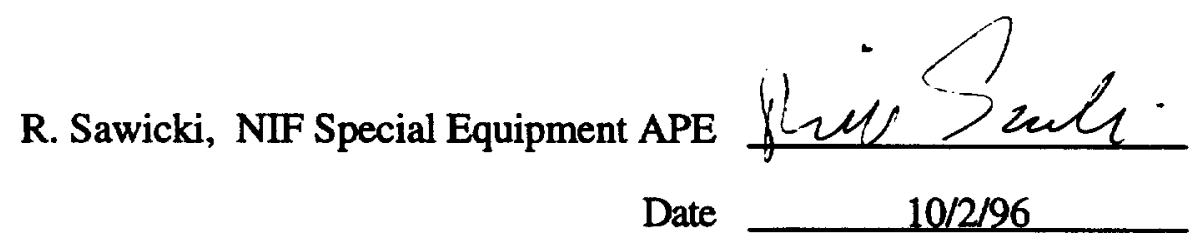

Level 4 Configuration Control Board Approval:

S. Kumpan, NIF Project Engineer

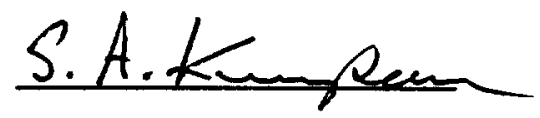

Approval Date

$10 / 23 / 96$ 


\section{Table of Contents}

\begin{tabular}{ll} 
Paragraph & Title \\
\hline 1.0 & Scope \\
2.0 & Applicable Documents \\
2.1 & Applicable NIF Project Documents \\
2.2 & Applicable US Government Orders, Codes, and Standards \\
2.3 & Applicable National Consensus Codes and Standards \\
2.4 & Applicable LLNL Standards \\
3.0 & Subsystem Description and Characteristics \\
3.1 & Subsystem Definition \\
3.1 .1 & Subsystem Description \\
3.1 .2 & Subsystem Functions \\
3.1 .3 & System Diagrams \\
3.1 .3 .1 & System Operating Modes \\
3.1 .4 & System Interfaces \\
3.1 .5 & Major Subsystems \\
3.2 & System Characteristics and Verification \\
3.2 .1 & Performance Characteristics \\
3.2 .1 .1 & Size and Mass Capacities \\
3.2 .1 .1 .1 & Size Capacities \\
3.2 .1 .1 .2 & Mass Capacities \\
3.2 .1 .2 & Target Positioning and Alignment \\
3.2 .1 .2 .1 & Target Positioning and Alignment Range \\
3.2 .1 .2 .2 & Target Positioning and Alignment Accuracy \\
3.2 .1 .2 .3 & Target Positioning and Alignment Stability \\
3.2 .1 .3 & Target Environment \\
3.2 .1 .3 .1 & Target vacuum environment \\
3.2 .1 .3 .1 .1 & Non-cryogenic targets \\
3.2 .1 .3 .1 .2 & Cryogenic targets \\
3.2 .1 .3 .2 & Cryogenic Target Environment \\
3.2 .1 .4 & Self-protection from Effects of Target Illumination \\
3.2 .1 .4 .1 & X-ray protection \\
3.2 .1 .4 .2 & Debris Protection \\
3.2 .1 .5 & Controls \\
3.2 .2 & Physical Characteristics \\
3.2 .2 .1 & Envelope \\
3.2 .2 .2 & Materials \\
3.2 .3 & Reliability, Availability, Maintainability \\
3.2 .3 .1 & Lifetime \\
3.2 .3 .2 & Replaceability \\
3.2 .3 .3 & Inherent Availability \\
3.2 .3 .4 & Reliability \\
3.2 .3 .5 & Maintainability \\
3.2 .3 .6 & Recovery from Abnormal Events \\
& \\
\hline & \\
\hline &
\end{tabular}




\section{Table of Contents}

\section{Paragraph}

3.2 .4

3.2.4.1

3.2 .4 .2

3.2 .4 .3

3.3

3.3.1

3.3.1.1

3.3.2

3.3.2.1

3.3.2.2

3.3.2.3

3.4

3.4 .1

3.4 .2

4.0

4.1

\section{Title}

Environmental

Ambient Temperature, Humidity, and Pressure

Vibration Environment

Electrical Noise Generation

Design and Construction

Hazard Classification

Natural Hazards Classification

Safety

Fail-safe Design

Radiation Protection

Robotic Systems Safety

Logistics

Spare Equipment

Maintenance Equipment

QA Provisions

Q-Level Assigned 


\subsection{Scope}

This Subsystem Design Requirement document is a development specification that establishes the performance, design, development, and test requirements for the target positioner subsystem (WBS 1.8.2) of the NIF Target Experimental System (WBS 1.8). 2.0 Applicable Documents

This section lists NIF Project Documents, DOE and other government orders, codes, and standards, and national consensus standards which are applicable to the Target Positioner Subsystem. Applicable LLNL standards are also being considered contingent upon the decision of final site selection.

\subsection{Applicable NIF Project Documents}

National Ignition Facility Functional Requirements and Primary Criteria, Revision 1.4, L-15983-3, February, 1996

National Ignition Facility System Design Requirement 003, Target Experimental System Design Requirements, Revision A, NIF-96-227, L-21706-01

"Proposed Metrication Policy for NIF," memo from R. Sawicki, NIF-LLNL-96-038, L-21248-01, 21 January, 1996

NIF-LLNL-93-044/L-15958-1, National Ignition Facility Quality Assurance Program Plan, November 1993

NIF Environmental, Safety, and Health Management Plan, November 1995, NIF-LLNL-95-599, L-20523-1

NIF Grounding Plan, NIF-LLNL-94-211, L-17346-1

NIF Procedure 1.6 : Assignment of Quality Levels

\subsection{Applicable US Government Orders, Codes, and Standards}

- 420.1 - Facility Safety

- N441.1 - Protection for DOE Radiological Activities

- 5400.5 - Radiation Protection of the Public and the Environment

- 5700.6C-Quality Assurance

- 5480.9-Construction Safety and Health Program

- 5480.10 - Contractor Industrial Hygiene Program

- 5480.11-Radiation Protection for Occupational Workers

- 10 CFR 835-Occupational Radiation Protection

- 29 CFR 1910 - Occupational Safety and Health Act (OSHA)

\subsection{Applicable National Consensus Codes and Standards}

ANSV/ASME B1.1 Standard for bolt threads

ASTM A307 Standard Specification for Carbon Steel Bolts an Studs, 60,000 psi Tensile Strength

ASTM A325 Standard Specification for High Strength Bolts for Structural Steel Joints

ASTM A36 Standard Specification for Structural Steel

ASTM A449 Standard Specification for Quenched and Tempered Steel Bolts and Studs

ASTM A490 Standard Specification for Heat-Treated Steel Structural Bolts, 150 ksi Minimum Tensile Strength

ASTM A6 Chemical analysis for structural steel

ASTM A751, F606 -testing methods for bolts and studs

ASTM D 3951 (packaging of bolts and studs)

ASTM F568, A563 Appurtenances for structural steel (nuts and bolts)

ANSI/RIA R15.06-1992; Industrial Robots and Robot System-Safety Requirements 


\subsection{Applicable LLNL Standards}

LLNL M-012 Rev 7, February 1993, "Design Safety Standards -Mechanical Engineering"

LLNL M-010, March 1989, "Health and Safety Manual"

LLNL M010, "Hazards Control Manual"

LLNL M-256 "Mechanical Engineering Design Practice"

LLNL "Mechanical Engineering Policy Procedures Manual"

\subsection{Subsystem Description and Characteristics}

\subsection{Subsystem Definition}

The Target Positioning subsystem (WBS 1.8.2) provides the hardware required to align the target accurately and repeatedly within the chamber at the focal point of the laser beams. Three assemblies will be provided, one for the target and two for the Target Alignment System (TAS) to handle both classified and unclassified targets. The target positioner assembly will be capable of accepting target assemblies incorporating either cryogenic or noncryogenic targets.

\subsubsection{Subsystem Description}

The Target Positioner consists of structures, mechanisms, and controls for mounting target assemblies exterior to the target chamber, transporting them to the chamber interior, positioning and orienting them at the chamber center, and providing favorable environmental conditions for their survival and functioning during all of the above.

The Target Positioner will enter the chamber in the horizontal equatorial plane, between the lowermost upper cone of laser beams and the uppermost lower cone. It consists, in the main, of an exterior tube, or housing, which has limited azimuthal and elevational mobility, and an interior shaft which moves radially for target insertion. The positioner is joined to the chamber with a vacuum gate valve to allow isolation of the exterior tube from the chamber. A flexible joint between the valve and the exterior tube allows for gross translational positioning. The exterior tube has access ports for mounting the targets to the inserter shaft, vacuum ports and valves for cycling between atmosphere and vacuum, and environmental control systems for target maintenance. The inserter shaft provides a standard mounting base for target systems, and incorporates mechanisms at the target end for fine translational and rotational positioning. It also incorporates a means for self-shielding from the effects of target illumination, including high fluences of $\mathrm{x}$-rays and debris.

Two similar assemblies will also be provided for the insertion of the Target Alignments System(s) (TAS(s)). These will incorporate some but not all of the elements described above. For example, the TAS will be withdrawn behind first wall protection prior to a shot, so will not require self-protection. Also, the environmental needs of the TAS are presumed to be less stressing than those of various target assemblies.

\subsubsection{Subsystem Functions}

The target positioner's functions are to mount, insulate, support, and insert targets for illumination. After insertion to a location near the chamber center, it positions the targets within a prescribed alignment envelope. The target positioner subsystem also encompasses the mechanisms for positioning the Target Alignment System (TAS). A major element of the functionality of this subsystem is the maintenance of positional stability. Additionally, both types of positioner encompassed herein will provide connections for some or all of the following services: electrical, instrumentation (both electrical and optical), vacuum, and fluids (including cryogens).

\subsubsection{System Diagrams}

\subsubsection{System Operating Modes}

Figure 3.1.3.1-1 identifies the sequence of operating modes planned for the NIF facility. The Tatget Positioner will also operate in all these modes, following the same scenario as the overall facility. 


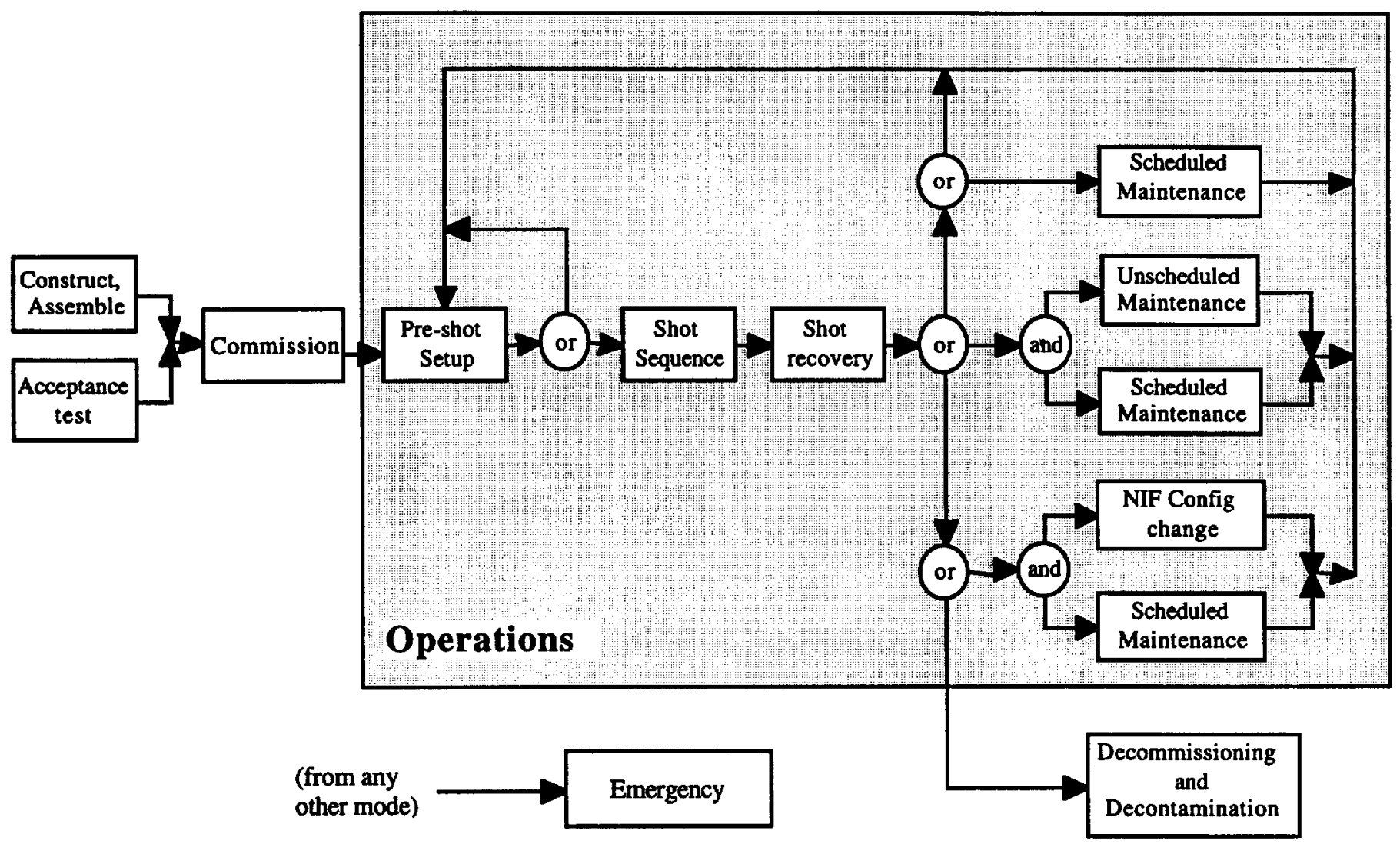

Figure 3.1.3.1-1 NIF operating modes

\subsubsection{System Interfaces}

The target positioner has major interfaces with:

Target Assemblies

Including mounts for non-cryogenic targets and cryogenic support subsystems (cryostats) for cryogenic targets.

The Target Chamber (WBS 1.8.1)

as regards attachment, geometry, vacuum isolation, vibration isolation, first wall protection (for withdrawn TAS positioners, etc).

\section{The Target Vacuum System (part of WBS 1.8.1)}

As regards compatibility of ablative materials for self-protection with subsequent pump down and reestablishment of chamber environment compatible with ensuing shots.

\section{The Chamber Center Referecnce System (WBS 1.7.1)}

Defines the location to which the target assembly is to be brought and positioned.

\section{The Target Alignment System (WBS 1.7.1)}

In two respects: provision of support via an insertion and positioning assembly and as the fiducial for the location and orientation of the target.

The Environmental Protection System (WBS 1.8.5.)

For in situ cleaning of the inserter(s) themselves, tritium monitoring and confinement (WBS 1.8.5.8). 
The Target Area Structures (WBS 1.8.4) and/or the Facility Target Building (WBS 1.2.2.2)

For sufficient foundation positional stability to meet requirements defined in paragraphs 3.2.1.1.3 \& 4, below.

\section{Target Auxiliary Systems (WBS 1.8.6)}

For transport of components and subassemblies to EPS area for cleaning.

Final Optics Assembly (WBS 1.8.7)

As regards stay out zones both within the chamber (defined by beam envelopes), and exterior (defined by final optics assembly hardware).

Diagnostics (WBS 1.8.3)

With regard to clear lines of sight to target region.

\section{Controls (WBS 1.5.)}

With regard to hardware and software controls, communication etc. to allow supervisory control to operate the facility during maintenance and target shots.

\section{Facility Auxiliary Systems (WBS 1.2.)}

With regard to special needs for capabilities in the Target Receiving and Inspection Building, General Assembly Building, Elecrtrico-mechanical Shop, and with regard to utilities needs.

\subsubsection{Major Subsystems}

Major components of the Target Positioner are:

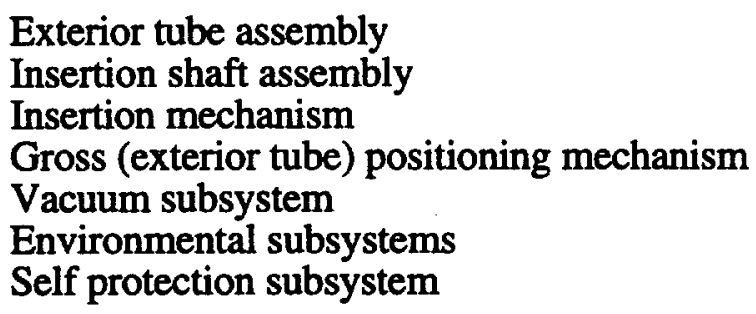

\subsection{System Characteristics and Verification}

The following sections define the minimum requirements which must be met by the Target Positioner Subsystem, related to performance, physical characteristics, etc. The approach for verifying that the design and the hardware meets each requirement is listed for each.

\subsubsection{Performance Characteristics}

\subsubsection{Size and Mass Capacities}

\subsection{Size Capacities}

The target positioner asembly shall be capable of mounting target assemblies of length not to exceed $2 \mathrm{~m}$, and of cross section bounded by a circle of $0.5 \mathrm{~m}<$ diameter $<$ TBD $\mathrm{m}$. NOTE that the configuration of target assemblies may be further restricted by considerations similar to those enumenrated in paragraph 3.2.2.1, following.

The positioner assemblies for the Target Alignment System(s) (TASs) shall be capable of mounting alignment packages of length not to exceed $0.3 \mathrm{~m}$, width not to exceed $0.25 \mathrm{~m}$, height not to exceed $0.25 \mathrm{~m}$, and girth not to exceed $1 \mathrm{~m}$. 


\subsection{Mass Capacities}

The target positioner assembly shall be capable of mounting target assemblies of mass not to exceed $200 \mathrm{~kg}$.

The positioner assemblies for the Target Alignment System(s) (TASs) shall be capable of mounting alignment packages of mass not to exceed $15 \mathrm{~kg}$.

\subsubsection{Target Positioning and Alignment}

\subsection{Target Positioning and Alignment Range}

The Target Experimental System shall be capable of holding and aligning targets within $\pm 5 \mathrm{~cm}$ of the nominal center of the target chamber (herein taken to mean the point in space defined by the Alignment Subsystem (see paragraph 3.1.4) as a reference for the aiming of fixed diagnostics devices) in three orthogonal translational degrees of freedom. The Target Experimental System shall be capable of holding and aligning targets in two orthogonal rotational degrees of freedom, about the target area $\mathrm{x}$ and $\mathrm{y}$ axes, respectively, within \pm TBD radians. The rotational requirement may be satisfied by initial rotations about centers other than the target center with subsequent translations (with three DOF) to reposition.

\subsection{Target Positioning and Alignment Accuracy}

The Target Positioner Subsystem shall be capable of placing and aligning targets at the desired position (within the positioning range) with an accuracy of $\pm 6 \mu \mathrm{m}$ for translational degrees of freedom, and with an accuracy of \pm 1 mrad for rotational degrees of freedom

\subsection{Target Positioning and Alignment Stability}

The Target Positioner Subsystem shall be capable of holding targets at their aligned location within $6 \mu \mathrm{m}$ and at their aligned rotation within $\pm 1 \mathrm{mrad}$ for two hours after alignment and before a shot. These limits shall be applied at the interface between the Target Positioner and the target assembly(ies) and/or the TAS(s). The positioner shall have the capability of repositioning to within these limits in the event of motion of the target relative to the positioner.

\subsubsection{Target Environment}

\subsection{Target Vacuum Environment}

\subsection{Non-Cryogenic Targets}

During mounting and insertion, targets shall be surrounded by a pressure of less than $5 \cdot 10^{-5}$ torr.

\subsection{Cryogenic targets}

During mounting and insertion, shrouded targets shall be surrounded by a pressure of less than $5 \cdot 10^{-6}$ torr.

\subsection{Cryogenic Target Environment}

The Target Positioner shall embody means for reducing the thermal radiation load on cryogenic target assemblies and support systems (cryostats) to less than $10 \mathrm{~mW}$. Such means may consist of providing coolant support for user-supplied liners cooled to an intermediate temperature $(\approx 80 \mathrm{~K})$ and/or intermediate radiation barriers ("superinsulation").

\subsubsection{Self-protection from Effects of Target Illumination}

The Target Positioner Subsystem shall provide for protection of itself and of portions of the mounted target assemblies. The protected region shall extend from a distance of no greater than 0.2 meters (plus the thickness of the protective materials themselves) from the target center to the chamber wall. Protection shall be provided against $\mathrm{x}$-rays and debris resulting from shots of up to $2.2 \mathrm{MJ}$ laser energy incident on the target, with DT fusion yields of up to $20 \mathrm{MJ}$. Damage resulting from shots with $20 \mathrm{MJ}<$ fusion yield $<45 \mathrm{MJ}$, shall be limited to acceptable levels consistent with RAM requirements. 
A design goal will be the provision of protection as above stated, but at a shorter distance (down to 0.1 meters) from the target center.

\subsection{X-ray Protection}

From a distance of 0.2 meters (plus the thickness of the protective materials themselves) from the target center outward, target assemblies and the Positioner proper shall be protected against the effects of $\mathrm{x}$-rays up to a cold fluence of $440 \mathrm{~J} \cdot \mathrm{cm}^{-2}$ for a period of $50 \mathrm{~ns}$.

Absolute protection shall be provided against ablation of the protected components, and sacrificial ablative material shall be of a type and amount so as to minimize negative impacts upon optical debris shields and the target chamber vacuum system.

Overpressures resulting from the ablation of sacrificial material shall be mitigated by the protective scheme to a level of 3 Megapascals at the $0.2 \mathrm{~m}$. distance.

Amounts of replaceable components which may also be activated by yield shots shall be minimized so as to minimize generation of low-level radioactive waste.

A design goal will be the provision of protection as above stated, but at a shorter distance (down to 0.1 meters) from the target center.

\subsection{Debris Protection}

From a distance of 0.2 meters (plus the thickness of the protective materials themselves) from the target center outward, target assemblies and the Positioner proper shall be protected against the impact of debris resulting from shots within the parameters specified in this section.

Absolute protection shall be provided against direct debris impact on the protected components.

Overpressures resulting from the impact of debris on the target-facing side of the protective material shall be mitigated by the protective scheme to a level of 3 Megapascals on the protected components at the $0.2 \mathrm{~m}$ distance.

Amounts of replaceable components which may also be activated by yield shots shall be minimized so as to minimize generation of low-level radioactive waste.

A design goal will be the provision of protection as above stated, but at a shorter distance (down to 0.1 meters) from the target center.

\subsubsection{Controls}

Control of the positioner's gross motion (target insertion), and fine positioning shall be effected from the facility control room. Monitoring of pertinent states (thermal, vacuum, etc.) shall also be done in the control room. Control design shall be compatible with, and in accordance with standards of, the Integrated Computer Control System (ICCS) (WBS 1.5).

A set of local controls shall be provided for operation of the positioners for initial set-up, alignment, maintenance, etc.

A means for manual extraction of the positioner with mounted target assembly from the target chamber shall be provided for use in the event of control system failure. 


\subsubsection{Physical Characteristics}

\subsubsection{Envelope}

The target positioner, when extended into the chamber, shall occupy a volume clear of the envelope of incident laser beams as well as the envelopes of $1 \omega$ and $2 \omega$ light un-intercepted by the target. Lines of sight requirements for various diagnostics shall also be respected. Target Positioner mechanisms and structures exterior to the chamber shall be clear of regions occupied by Final Optics Assemblies. These requirements shall apply to the laser geometry required to support both indirect and direct illumination experiments.

\subsubsection{Materials}

Activation of all Target Positioning materials shall be limited such that personnel reentry to the target area is possible within 4 days after a shot with 20 MJ DT fusion yield.

As a goal, the target positioner should be approachable for hands-on servicing no more than 24 hours following a high-yield $(20 \mathrm{MJ})$ shot, for $2 \mathrm{hrs}$ of servicing, without violating any of the radiation protection provisions as stated in requirement 3.3.2.2.

\subsubsection{Reliability, Availability, Maintainability}

\subsubsection{Lifetime}

The Target Positioner Subsystem shall have a design lifetime of 30 years.

\subsubsection{Replaceability}

Any portion of the target positioner subsystem which cannot reasonably be designed for 30 year lifetime shall be designed to be replaced or repaired at reasonable cost in a timely manner consistent with the overall availability of the target chamber subsystem as stated in 3.2.3.3 and 3.2.3.5.

Interchangeability of target chamber subsystem components shall be preserved. All components with the same part number shall be interchangeable.

\subsubsection{Inherent Availability}

The target positioner subsystem shall have a shot availability of at least $99.91 \%$. The system is unavailable when it is undergoing unplanned maintenance. Unplanned maintenance includes failure detection and active repair as well as logistic and administrative downtimes.

\subsubsection{Reliability}

The target positioner subsystem shall have an overall reliability of $99.96 \%$. Reliability is defined as the probability of meeting the minimum requirements of the experiment per no-yield shot as stated in SDR2:3.2.3.4.

\subsubsection{Maintainability}

The ttarget positioner subsystem shall have a scheduled maintenance plan that fits within an overall annual plant goal of 69 days. The unplanned maintenance goal is 6 hours per year. Opportunistic maintenance activities are performed between shots and during other system downtimes.

\subsubsection{Recovery from Abnormal Events}

The time required for the target positioner subsystem to recover from any abnormal event shall be less than the maximum times cited below, as a function of the expected yearly frequency of occurrence of the event.

\begin{tabular}{|c|c|}
\hline $\begin{array}{c}\text { Expected Frequency of Occurrence Per Year, F } \\
\qquad \begin{array}{c}F \geq 1 \\
1>F>1 \bullet 10-2 \\
1 \cdot 10-2>F \geq 5 \cdot 10-4\end{array}\end{array}$ & $\begin{array}{c}\text { Maximum Recovery Time } \\
24 \text { hours } \\
1 \text { week } \\
3 \text { months }\end{array}$ \\
\hline
\end{tabular}


Probabilities listed in DOE-STD-1020-94 shall be used for natural phenomena.

For frequent events, the maximum allowed recovery time may be restricted by availability requirements to be less than that shown in the table above.

\subsubsection{Environmental}

The site for NIF has not yet been selected. The present design is therefore non-site-specific. For the purpose of Title I design of the Target Experimental System, it shall be assumed that NIF will be constructed at a site with the general infrastructure as available at candidate sites. Specific environmental assumptions are listed in the following sections.

\subsubsection{Ambient Temperature, Humidity, and Pressure}

All Target Positioner Subsystem components shall meet all requirements when operated at a temperature of $20^{\circ} \mathrm{C} \pm$ $0.3^{\circ} \mathrm{C}$, a relative humidly of $30 \%$ to $60 \%$, and a pressure equal to ambient atmospheric pressure $\pm 10 \mathrm{~cm}$ water (to accommodate negative air system).

\subsubsection{Vibration Environment}

The Target Positioner Subsystem shall meet all requirements, while being exposed to ambient random vibration of $1 \mathrm{e}^{-10} \mathrm{~g}^{2} / \mathrm{Hz}$, from 1 to $200 \mathrm{~Hz}$, applied at the floor surface of the foundation of the target area building.

\subsubsection{Electrical Noise Generation}

The Target Positioner Subsystem shall not generate electrical noise at TBD level over a TBD spectrum to be defined as TBD during the following TBD phases of operation.

The Target Positioner Subsystem shall adhere to the NIF Grounding Plan referenced in section 2.1.

\subsection{Design and Construction}

\subsubsection{Hazard Classification}

The NIF shall be designed and operated as a low-hazard, radiological facility. The inventory of key radionuclides shall not exceed the limits defined in the Preliminary Hazards Analysis, and cited below

\subsubsection{Natural Hazards Classification}

The Target Positioner Subsystem shall meet the performance class 2 (PC2) design goals in DOE-1020. Though not required by DOE-1020 PC2, dynamic seismic analysis shall be performed. Additional requirements on the allowed recovery time from abnormal events are cited in 3.2.3.

\subsubsection{Safety}

The Target Positioning Subsystem shall be designed, constructed, and operated as part of the Target Experimental System such that it is a low-hazard, radiological component thereof. Compliance with this classification shall be verified through a Preliminary Hazard Analysis assessment of bounding accidents involving those radionuclides and/or chemicals presenting the most significant hazards (see 10 CFR 830.110 Nuclear Safety Management, Safety Analysis Report, and DOE Order 5481.1B, Safety Analysis Review System). Administrative controls shall be established prior to $\mathrm{KD} 3$ to ensure that inventory limits for a radiological low-hazard, non-nuclear facility are not exceeded.

Unless otherwise specified herein, the Target Positioning Subsystem shall meet the requirements of the LLNL Mechanical Engineering Design Safety Standards, Electrical Engineering Design Standards, and laser safety standards.

\subsubsection{Fail-safe Design}

Wherever reasonably possible, the Target Positioner Subsystem shall be designed to fail safe upon inadvertent loss of power, coolant (including cryogens), or other failure. 


\subsubsection{Radiation Protection}

The Target Positioner Subsystem shall be designed so as to support the requirements on the Target Experimental Systems for control of ionizing radiation doses to the public as spelled out in the parent SDR.

The ALARA (as low as reasonably achievable) principle shall be utilized in both design and operation of the subsystem to eliminate unnecessary radiation dose to workers in the Laser and Target Area Building, collected employees, and visitors from both routine and off-normal operations. Radiation protection shall include: shielding; control of workplace ventilation; monitoring of personnel for external and intemal radiation dose; establishment of a routine contamination monitoring program including air monitoring; and the proper containment of radiation and radioactive materials.

The radiation shielding design for the Target Positioning Subsystem shall be more cbnservative than required by DOE Order 420.1, Facility Safety, in that maximum doses to an individual worker shall be limited to one- tenth (shielding design goal) of the occupational external dose limits specified in 10 CFR 835 .

The requirements for radiological safety in DOE Order 420.1, Facility Safety; should be incorporated when they are determined to be cost effective.

\subsubsection{Robotic Systems Safety}

Robotic systems within the Target Positioner Subsystem shall comply with the requirements of ANSI/RIA R15.06-1992; Industrial Robots and Robot System-Safety Requirements.

\subsection{Logistics}

\subsubsection{Spare Equipment}

As a part of the design/construction project, the Target Positioning Subsystem shall provide an initial compliment of spare parts as required to activate the system.

\subsubsection{Maintenance Equipment}

As a part of the design/construction project, the Target Positioner Subsystem shall provide all equipment required to inspect, service, and maintain all of its components to meet the maintainability and availability requirements in \$3.2.3. Maintenance equipment shall include all handling fixtures, lifting equipment, and other special tools not otherwise available within NIF, that are necessary to perform any planned (scheduled or unscheduled) maintenance activity.

\subsection{QA Provisions}

\subsection{Q-Level Assigned}

\begin{tabular}{|c|c|c|c|c|c|}
\hline \multirow[t]{2}{*}{$\begin{array}{c}\text { WBS } \\
\text { element } \\
\text { number }\end{array}$} & \multirow[t]{2}{*}{ WBS element title } & \multicolumn{3}{|c|}{$\begin{array}{l}\text { Assigned } \\
\text { Q-level }\end{array}$} & \multirow[t]{2}{*}{ Why not Q-level 3 ? } \\
\hline & & 1 & 2 & 3 & \\
\hline 1.8.2.1 & Inserter / Positioner & & $\sqrt{ }$ & & $\begin{array}{l}\text { precision mechanical assembly, } \\
\text { unusual materials of } \\
\text { construction, }\end{array}$ \\
\hline 1.8 .2 .2 & Vacuum Chamber & & $\sqrt{ }$ & & $\begin{array}{l}\text { critical vacuum seal performance } \\
\text { required }\end{array}$ \\
\hline 1.8 .2 .3 & Structural Support & & $\sqrt{ }$ & & precision mechanical positioners \\
\hline 1.8 .2 .4 & Control System & & & $\sqrt{ }$ & \\
\hline
\end{tabular}




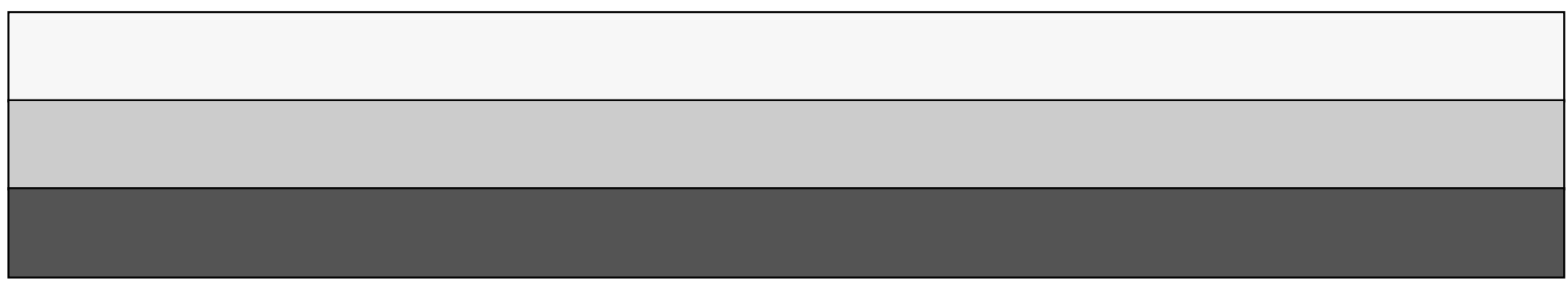

